\title{
CONSIDERATIONS ON RENEWABLE ENERGY SOURCES AND THEIR RELATED PERSPECTIVES OF AGRICULTURAL ENGINEERING
}

\author{
Ester Foppa Pedretti, Giovanni Riva, Giuseppe Toscano, Daniele Duca
}

\section{Background}

The need for raising the quota of energy produced from renewable sources in the global energy balance, dominated by developed countries, is supported by a huge and growing body of literature - today easily and largely accessible ${ }^{1}$ through the World Wide Web - and by the international legislation, where this need has finally come to be viewed as a priority. An important example is the recent EU directive promoting the use of energy from renewable sources [2009/28/EC]. Therefore, this contribution does not analyse studies or data to demonstrate the importance of renewable energy sources, which is assumed as a given, but rather discusses issues that are relevant to those who deal with the subject at the educational and the professional level, with special emphasis on Agricultural Engineering.

Before delving into the subject, it may be useful to summarize the main issues involved:

a) The first is the reported shrinking of fossil fuel supplies that can be extracted at reasonable cost (especially crude oil with a low content of pollutants, such as sulphur, available at technically reachable depths). The matter is debated, because evidence for dwindling world supplies ${ }^{2}$ [Briassoulis 2009] due to rising demand coexists with arguments maintaining that such resources are plentiful, but substantially conditioned by geopolitical matters, trade dynamics, and the investment policies of the oil industry ${ }^{3}$ [Maugeri 2006]. In this context, the development of renewable energy sources to replace fossil fuels has the potential to

Paper received 11.11.2009; accepted 30.08.2010

Prof. GIOvanni Riva full professor, Dept. SAIFET, Technical University of Marche, via Brecce Bianche, Monte Dago, 60131, Ancona, g.riva@univpm.it

Prof. Ester FopPa PEDRETTI associate professor, Dept. SAIFET, Technical University of Marche, e.foppa@ univpm.it

Dr. Giuseppe Toscano researcher, Dept. SAIFET, Technical University of Marche, g.toscano@univpm.it

Dr. DANIELE DucA, PhD, Dept. SAIFET, Technical University of Marche,d.duca@univpm.it reduce the global dependence on them, which is a strategic value in itself;

b) The second is the environmental issue connected with $\mathrm{CO}_{2}$ and other greenhouse gas emissions, due to the manufacturing and use of technologies and industrial products (particularly $\mathrm{N}_{2} \mathrm{O}$ and $\mathrm{CH}_{4}$ ). These are inducing climate change (for which the evidence is substantial), resulting in an altered balance of multiple ecological systems as well as in social consequences, especially in the poorest countries [Global Humanitarian Forum 2009]. The use of fossil fuels essentially moves the carbon that has accumulated under the surface of the earth to the atmosphere, inducing changes in its chemicalphysical characteristics, like higher permeability to infrared radiation. Views differ about these aspects, too, some researchers anticipating multiple severe consequences [Flannery 2008] and others relating these changes to natural climate cycles [Various Authors 2009]. However, support for the latter view appears to be less strong. At the political lev$\mathrm{el}$, the issue has long been discussed ${ }^{4}$, although greater consistency between policies and interven-

\footnotetext{
${ }^{1}$ A Google search for "renewable energy" (with the string in inverted commas in order to search for the words in this sequence) yields more than 17 million (M) hits; a search for "energy" produces more than $350 \mathrm{M}$ hits, placing it in reassuring competition with "food" (over $600 \mathrm{~m}$ hits). However, when limited to PDF files (i.e. documents available for download, which are likely to be reports of a certain value), the search yields more than $3 \mathrm{M}$ hits for "renewable energy" and less than $55 \mathrm{M}$ for "food". These data, confined to the English language, are partial but highlight various questions, in particular the huge amount of material available on the Web. Its sheer quantity would require a summarizing effort directed at identifying relevant material for teaching purposes and for spreading research results.

2 This view is widely held, with Hubbert a major points of reference (http://www.hubbertpeak.com). Given the scarcity of fossil resources, some authors propose focusing EU university curricula on "renewable energy sources" and "agricultural engineering".

3 This view has a narrower following but the literature is usually highly qualified.

${ }^{4}$ Among various actions, one in particular deserves to be mentioned - the setting up of the Intergovernmental Panel for Climate Change (IPCC), whose remit is to study climate change and its causes. At the EU level the IPCC reports have led to an articulated body of rules aimed at reducing $\mathrm{CO}_{2}$ emissions that will become increasingly restrictive over time.
} 


\begin{tabular}{|l|l|l|l|l|l|}
\hline Item/Year & 2005 & 2006 & 2007 & 2008 & 2009 \\
\hline No. of plants & 2,600 & 3,500 & 3,710 & 4,000 & 4,700 \\
\hline Electrical capacity installed (Megawatt, MW) & 650 & 1,100 & 1,270 & 1,200 & 1,400 \\
\hline Electrical energy produced (Terawatt/hour/year, TWh/y) & 2.8 & $>5$ & 7.4 & 8.2 & 10.8 \\
\hline Proportion of national electricity production (\%) & 0.5 & $>1$ & 1.4 & 1.6 & 2 \\
\hline Turnover of the industry (billion $€$ ) & 0.5 & 1 & 0.65 & 0.6 & 1.05 \\
\hline Turnover of operators (million $€)$ & 360 & 650 & 750 & 800 & 1,000 \\
\hline Jobs & 5,000 & 10,000 & 10,000 & 10,000 & 10,500 \\
\hline $\mathrm{CO}_{2}$ reduction (million tonnes/y) & 2.5 & 5 & 6.4 & 7 & 9.3 \\
\hline
\end{tabular}

TABLE 1 - Highlights of the development of the German biogas industry (adapted from Möller 2009).

tions on the one hand, and between statements and formal commitments on the other is being demanded from many quarters. From this point of view, renewable energy sources appear to be among the principal means to reduce $\mathrm{CO}_{2}$ emissions. The environmental issue could be advanced by making $\mathrm{CO}_{2}$ production caps mandatory, thus reducing carbon-rich fuel consumption regardless of their being plentiful or otherwise ${ }^{5}$;

c) The third issue is socio-economic. Developed countries, hit by the recession and by competition with developing countries, which gain increasingly large market shares, view renewable energy sources and energy conservation as a field with a large potential for development, where appropriate political action could stimulate economic recovery in several production sectors [UNEP 2009]. A successful example is energy development from biogas in Germany. Originally conceived to provide an alternative to the poorly competitive livestock farms in post-reunification Eastern Germany, biogas generation from farm crops has promoted the development both of the relevant technology and of a vital industry ${ }^{6}$ [Möller 2009], as summarized in table 1 .

\section{Key topics}

Some key issues are synthetically discussed below

\footnotetext{
5 This has promoted geoengineering studies and pilot projects to capture $\mathrm{CO}_{2}$ from the atmosphere and store it either underground, e.g. in exhausted oilfields, or in the oceans. These solutions are controversial for their cost, the long-term reliability of sequestration, and the potential environmental problems connected with any leaks, e.g. seawater acidification.

${ }^{6}$ In 2007, according to the Biogas Zentrum (http://www.biogaszentrum.de/) and to the German Biogas Association (http://www.biogas.org/), over 1,000 companies including manufacturers, planners, turn-key project providers, operating and contracting companies as well as traders, financing and research institutions were involved in the field, which provides an estimated 10,000 jobs. In 2006 the industry's turnover exceeded 1 billion euros for the first time. At the end of 2007 over 3,700 biogas production plants were in operation, with an installed capacity of about 1,300 MW and energy sales of 750 million $€$. Möller 2009 predicts that the plant number will grow to 5,000 in 2009.
}

in relation to the need for promoting renewable energy sources and to the development of Agricultural Engineering in Italy. Three related issues concerning different fields are addressed:

a) Current perceptions about renewable energies vs. energy from fossil fuels, and their relevance from a teaching perspective involving both university and general education;

b) the close connection between renewable energy sources and energy conservation in view of a larger role for the agricultural sector which, based on the proposals detailed here, should increasingly be viewed as an interface with the other sectors (industrial and civil), also in relation to energy production;

c) biotechnologies, one of the critical elements of biosystems, which apply advanced production methods to natural resources, starting with crops. Biofuels (liquid fuels derived from biomass) are much debated biotechnology products with a great potential for development, which are therefore an interesting new frontier for Agricultural Engineering. The controversial relationship between food and energy crops is not addressed here.

\section{Current perceptions about renewable energies vs energy from fossil fuels}

\subsection{Background}

It is always difficult to clarify the full scope of the energy issue and the characteristics of the different energy sources both in teaching settings and when promoting innovative projects on the territory. The problem is apparently trivial, the success of energy projects - both large and small - being increasingly related to public acceptance of data and basic assumptions. This applies to problems such as persuading even a small community of the benefits of a biomasspowered district heating plant with a thermal power of a few MW as well as to the market penetration of technologies that involve individual use (e.g. solar power plants with a surface of a few square metres for the production of sanitary hot water designed for single households).

Although economic feasibility is clearly the most 
efficient lever for the adoption of technological projects and products by users, the correct development of renewables also requires a certain level of general knowledge and an acceptance of the limitations and/or problems that nearly always come with any new concept. Those who are involved in energy analyses on the territory or are in consistent contact with users often note that the energy problem is underestimated, i.e. few people realize the "value" of consumption in terms of resources used, even those whose jobs are in energy and/or environmental analyses or energy production. In contrast, the majority of the population appears to be aware of the need for replacing traditional energy sources, even though they often underestimate the practical problems. As a result most people, including the best educated, believe that the current levels of fossil fuel consumption are easily replaceable with renewables, albeit at a different economic cost.

This widespread perception is thought to be at the root of the modest results obtained so far in curbing the consumption of energy of fossil origin in Italy (see paragraph 4) and of the modest penetration of plants powered by renewable energy sources, which is not going to be sufficient to meet EC objectives.

Some aspects are analyzed below.

\subsection{Perceptions about the consumption of energy from fossil fuels}

Energy is a concept that is not easily understood by the general public in spite of the straightforward nature of some of its definitions. In the context of this work, energy is mainly considered as thermal, electrical and primary energy. Electrical energy derives nearly always from thermal energy, both of which are required by final users, especially at fixed user points. Energy from fuels can always be expressed in the form of primary energy; it is necessary for transportation, therefore it is required by vehicles. In a country like Italy the energy consumed for road transport accounts for a sizable fraction of the total energy. Primary energy is essentially the amount of crude oil that is needed to obtain the same effect in the form of heat, electricity or mechanical energy through energy conversion technologies. Food energy encompasses food and/or feeds, and is generally related to the surface area required to grow edible raw materials.

In terms of calorific value, $i$ ) the temperature of 2,000 litres of water can be raised by about $4.2{ }^{\circ} \mathrm{C}$ using $1 \mathrm{~kg}$ of diesel fuel and a medium-performance boiler; ii) $1 \mathrm{~kg}$ of diesel fuel contains the energy required for an adult to survive for over 3 days; and iii) a hectare of land sown with wheat can provide food for nearly 8,000 days/person, which is equivalent to nearly 2 tonnes of oil.

Since, in the authors' experience, statement $i$ ) fails to impress most students from the Italian science faculties; explaining the phenomenon is therefore not unimportant. Statement ii) elicits surprise, because it is closer to daily life; the surprise lies substantially in the realization that $1 \mathrm{~kg}$ of diesel fuel theoretically meets the energy requirements of a human being for a long time, whereas a car burns it in a matter of minutes. Statement iii) highlights an unexpected relationship between food/feed energy and the energy requirements of industrial and civil infrastructures, downsizing the production potential of the land.

Although this simplistic framework becomes considerably more complex if the indirect forms of energy used in the different production processes (especially the energy required to grow raw food materials) are entered, the conclusions in qualitative terms are identical.

An awareness of the energy intensity of the various phenomena allows realization of the present huge energy needs and of their rising trend, a key factor when trying to achieve significant public participation in energy planning for small districts or whole countries.

From the teaching standpoint, the authors have found that exercises where energy is expressed in the form of the power developed by a human being, a work animal and a machine, and the amounts of raw materials (fuel and food) required to feed them are quantified, are particularly useful. These tests aim at putting energy consumption in perspective, in the same way as the size of the furniture bought for a room. The copious literature on these aspects also shows that traditional (or old) units, which involve specific measures for each type of energy (e.g., "hp" and "hph" for power and mechanical energy), are easier to learn- at least initially, which is not negligible than the International System, where J and W apply to all forms of energy, but are more useful to those who are familiar with the field.

\subsection{Perception of the potential of renewable energies}

With few exceptions, most sources of renewable energies are diffuse, like solar energy and biomass; exceptions include high-temperature geothermal energy, available at shallow depths in few places in the world.

It is essential to be aware that the energy that can be obtained from renewable sources far exceeds the world's consumption. It has been written (and one can also autonomously assess) that the global arable land can provide $800 \times 10^{18} \mathrm{~J}$ (800 EJ) of biomass energy, and more than 1,000 EJ if marginal territories are included, without adversely affecting food production. Since current global consumption is around $400 \mathrm{EJ}$ [Berndes 2003; Hoogwijk 2003], the biomass potential is about twice the present needs.

Statements to this effect are generally used to introduce the argument and are probably reassuring, since they lead to think that important, even unimaginable results can be achieved with renewable sources (this is usually the aim of those who quote them). This view is indeed widely shared. The difficulty lies in making the 
public aware that the problems to be addressed in the short term to make available even a fraction of such resources are so huge that they require rethinking the organization of the developed world.

In addition, such global estimates (besides requiring an audience familiar with exponential numbers to the $18^{\text {th }}$ power) do not take into account the gains achievable from reducing consumption through energy conservation, which is essential from a cultural viewpoint. This aspect is addressed in paragraph 4 .

To return to the perceived potential of renewable energy sources, in the current situation we have on the one hand available fossil resources through the exploitation of large oilfields and complex and capillary processing and distribution networks, and on the other renewable resources characterized by:

- discontinuity over time, i.e. production connected with given (solar energy) or only partially modifiable (biomass) natural cycles. Discontinuity can be resolved by stocking raw materials or processed products, or the energy itself, but it entails a cost;

- limited specific intensity in terms of unit of surface area or other spatial parameters, i.e. unlike oil and electricity the energy would be obtained from very wide spaces (usually large surfaces) if renewables are to replace fossil sources, which may not be feasible given the current land use in urbanized areas.

The ongoing review of the energy supply by developed countries therefore starts from this last consideration. Most assessments recommend developing a diffuse generation of the energy used by final consumers (in particular heat and electricity). This stance has fed a strong cultural current (e.g. [Rifkin 2002]) and stimulated research in ad hoc technologies, such as small and micro cogenerations, which are the subject of important provisions (e.g. [European Commission 2008]). Given the current energy market trends, these generation models will take time to get established as well as adequate legal provisions and user awareness.

The above considerations regarding the field of renewable energy sources again highlight the importance of teaching, where Agricultural Engineering can provide an essential contribution.

\section{The renewable energies/energy conservation question and the potential role of agriculture}

\subsection{Background}

Several types of renewable energy plants, like large photovoltaic power plants and biomass-fuelled thermal electric power plants without heat recovery, often feed the energy into the grid. But just as often specific users are required, as in the case of solid biomass-fuelled district heating plants and of solar thermal power plants serving individual households. In these cases the introduction of renewables is often viewed as a separate issue, apparently unrelated with the con- sumption levels of the users served. Typically, the final data of pilot plants or feasibility studies quantify the fossil energy saved by its replacement with renewable sources, which can be total, as with biomass district heating, or partial, as with solar thermal power plants.

The fact that renewable energies are limited (inherently, like biomass, or due to their diffusion in an area, like solar power) influences their cost. It would therefore be logical to downsize energy consumption when considering their adoption ${ }^{7}$. In principle, with investments staying the same, this would achieve at least a reduction in overall energy consumption and an increase in the quota from renewable sources.

This commonsense consideration is unfortunately often neglected, reflecting the persistence of a fairly serious cultural problem.

An important item in Italy is the energy required by residential and office buildings, which together with transport account for a large amount of the consumption, at least in those areas where homes must be heated or cooled ${ }^{8}$. The two case studies reported below, taken from two European research projects in which some of the authors were involved, were carried out in Lombardy [ASPIRE 2007; WISE PLAN 2006], and highlight these issues as well as the potential role of the farming sector, and consequently of Agricultural Engineering.

\subsection{Case study 1: Comunità Montana di Scalve (CMS)}

The Comunità Montana di Scalve (Scalve mountain community), at the north-eastern end of the Bergamo province (fig. 1), is a territorial body established in 1973. It borders with the Sondrio and Brescia provinces; its four municipalities extend over 140 $\mathrm{km}^{2}$, with a population of ca. 4,500 and about 400 small firms and bodies employing 1,300. There are 58 farms covering about 3,600 ha (essentially pastures) and 650 head of cattle, as well as sheep and goats. This zone is representative of pre-alpine areas; it is well preserved, with solid rural activities and tourism, and a population that is well rooted in the territory.

Energy consumption can be subdivided into the typical users: buildings (households, public offices and services), industry, farming, and transportation. The energy balance is shown in figure 2 . Local energy production is high, from wood (about 3 ktoe) and from water, with 6 hydroelectric plants (overall ca. 10 $\mathrm{MW}$ ) producing $36 \mathrm{GWh} / \mathrm{year}$, most of which is exported. Gross consumption of global primary energy

\footnotetext{
${ }^{7}$ Obviously, the process can be more or less intense, based on the energy consumption criteria and standards to be adopted or made binding through special provisions.

${ }^{8}$ The continuously growing electricity component, in the form of primary energy, consumed by buildings all over the country (around $10 \%$ in northern Italy) is reducing the gap between northern and southern Italy.
} 
exceeds 16.7 ktoe/year, or about 3.7 toe/inhabitant (greater than the national average of ca. 3.3 toe). The quota from renewables is $26 \%$ (vs about $6 \%$ at the national level) and would be $40 \%$ if the exported green electricity were included. Consumption is dominated by buildings $(35 \%)$ and transport $(56 \%)^{9}$.

The research demonstrated a high consumption of thermal energy by households, public and services users, with a specific yearly consumption of primary energy of $265 \mathrm{kWh} / \mathrm{m}^{2} 10,11$. Italian regulations [leg. decree no. 192, 2005; leg. decree no. 59, 2009] set a cap consumption of $145 \mathrm{kWh} / \mathrm{m}^{2}$ for new buildings ${ }^{12}$ in this climate zone. The abundance of renewable energy sources in the CMS compared with the Italian average is therefore offset by the low energy efficiency of buildings. The data summarized in figure 2 (including hydroelectric energy) allow for a calculation of a $65 \%$ quota of renewables for heating buildings, which would rise to $88 \%$ if buildings met the above limits, which are not strict.

In this context the local stakeholders have preferred a plan to extend photovoltaic plants and to build a small district thermal plant (1.5 MW) to measures improving building energy efficiency (the power plants are yet to be built).

This situation is found in several areas served by biomass-fuelled district heating, which are indicated as virtuous examples ${ }^{13}$ accounting today for over 250 MW of thermal energy, 110,000 households and 450,000 inhabitants in Italy.

Finally, the energy requirements of farming are trifling compared with its considerable possibilities to contribute, together with forestry, to the other sectors. Further considerations are discussed below.

\subsection{Case study 2: Parco del Ticino}

Parco del Ticino encompasses a very large area $\left(914 \mathrm{~km}^{2}\right)$ that is highly representative of Lombardy and accounts for $4 \%$ of its area. It includes 47 municipalities belonging to the provinces of Varese, Milan and Pavia and 440,000 residents, or $5 \%$ of the region's inhabitants. Parco del Ticino is less urbanized than the rest of the region, with a greater proportion of arable land, forests, and watercourses. However, important social and economic realities are also found

${ }^{9}$ A situation typical of suburbs, where modest local services involve high mobility, mostly by own means of transport.

10 Only households, since consumption by seasonal homes is reduced by the limited period of use.

${ }^{11} \mathrm{The} \mathrm{kWh} / \mathrm{m}^{2}$ (primary energy) is used due to its adoption in Italian regulations.

${ }^{12}$ All buildings.

${ }^{13}$ One of the problems of biomass-fuelled district thermal plants is to find the feedstock. Improving building energy efficiency would partially address it. However, the difficulties are various and complex. Here are two examples: (i) the fear of the company running the plant of dwindling energy sales and, consequently, plant turnover; (ii) the difficulty of launching such programs, which require both the involvement of users and the availability of funds. within its boundaries, like the Malpensa International Airport and the Turbigo power station (1,750 MW of electricity, currently fuelled by natural gas).

Farming involves more than 46,000 ha, or $51 \%$ of the surface, with 1,400 farms and about 30,000 head of cattle, besides animal rearing (mainly swine and aviculture); forests extend over more than 5,000 ha. The significant farming sector and thriving tertiary and industry ${ }^{14}$ set Parco del Ticino apart from the CMS, making it a typical area of the north Italian plain.

Figure 4 shows the energy balance, from which a total gross consumption of primary energy of almost 1.46 Mtoe (3.3 toe/year/inhabitant) is inferred. The incidence of renewables is $12 \%$. Besides,

- ca. $97 \%$ of the primary energy is imported from outside (ca. $87 \%$ is natural gas);

- ca. $75 \%$ of the primary energy consumed in the area is used to produce electrical energy; ca. $87 \%$ of the latter (in terms of primary energy used) is produced in the Turbigo power station and most is exported $(83 \%)$;

- the civil sector (households, public buildings, and services) accounts for about $55 \%$ of the final consumption (the alone households consuming 30\%) and the industrial sector for about $16 \%$;

- transport absorbs ca. $24 \%$ of the final consumption ${ }^{15}$;

- farming has a marginal role in energy consumption. However, it can become a producer, which may be interesting both in terms of the contribution itself and for the example it can set ${ }^{16}$.

To sum up, the major categories of gross energy consumption in terms of amount, possibilities for action and impact in the area are: production of electrical energy, buildings, and transport. Household heating accounts for an average consumption of 155 $\mathrm{kWh} / \mathrm{m}^{2}$. The legal consumption limit for new buildings in this climate zone is about $110 \mathrm{kWh} / \mathrm{m}^{2} 17$. Besides, energy auditing of municipal buildings - some of which underwent renovation through the installation of renewable energy plants (solar panels, heat pumps and cogeneration) - showed that in 8 public buildings found in 4 municipalities (accounting for about 23,000 inhabitants) consumption was higher than in households ${ }^{18}$ (up to $300 \mathrm{kWh} / \mathrm{m}^{2}$ ), despite the less intense occupancy.

\footnotetext{
${ }^{14}$ With the exception of energy production, the local industry is characterized by low energy consumption.

15 Consumption by the transport sector is difficult to assess, because Parco del Ticino is intensely criss-crossed, whereas movement within its boundaries is more limited. Similarly, the consumption related to the Malpensa airport is not easily assessed and cannot be attributed with accuracy to a limited area such as this.

${ }^{16}$ Lombardy officials have estimated that biogas plants can produce more than $200 \mathrm{MW}$ of electricity.

${ }^{17}$ All existing buildings.

${ }^{18}$ In this case, a 5\% increase in household energy efficiency would involve a reduction of about 18,700 toe (ca. $1.5 \%$ of the total final energy consumption of Parco del Ticino), or 45-50,000 tonnes of $\mathrm{CO}_{2}$.
} 


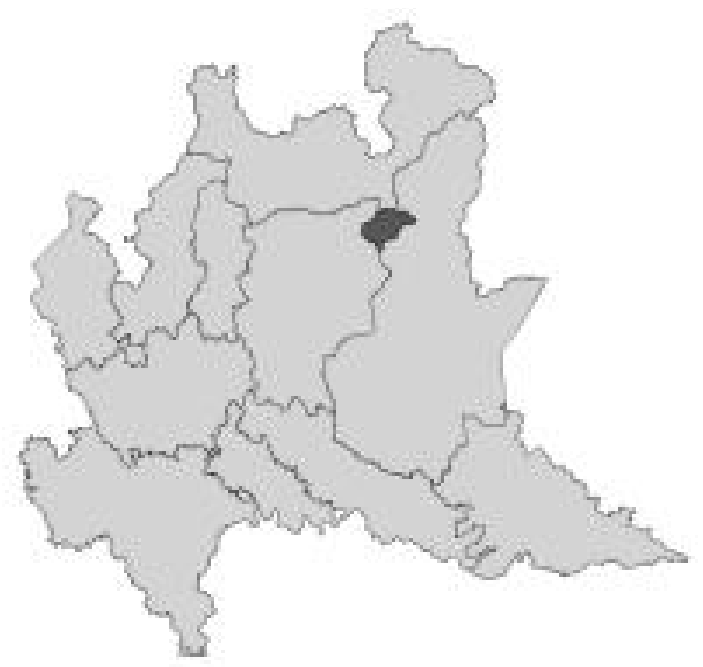

Fig. 1 - Location of Comunità Montana in Lombardy.

Also in this context then, buildings are large energy consumers, and any intervention in this sector should include both energy conservation measures and the introduction of renewable energy sources (tab. 2). Again, the energy requirements of farming are negligible compared to its potential role.

\subsection{Considerations}

The following conclusions can be drawn from these case studies:

- effective reduction of energy consumption and its environmental impact requires both energy conservation and renewable energies to be introduced, starting with the former. Today, the opposite is often done, with the potential residing in curbing consumption sometimes being completely overlooked;

- energy consumption assessments and the measures to be adopted should address districts with different sizes and characteristics as a whole, especially in countries, such as Italy, where production activities are highly integrated compared with other developed countries. This approach offers the advantage of highlighting the aspects that most need action and might be overlooked by narrower (sector) analyses;

- farming, though important in terms of the surface area occupied, usually accounts for a fairly low or even negligible proportion of the energy consumed. However, adequate analyses like those described here show that it could come to offer a significant contribution to the other sectors by provid-

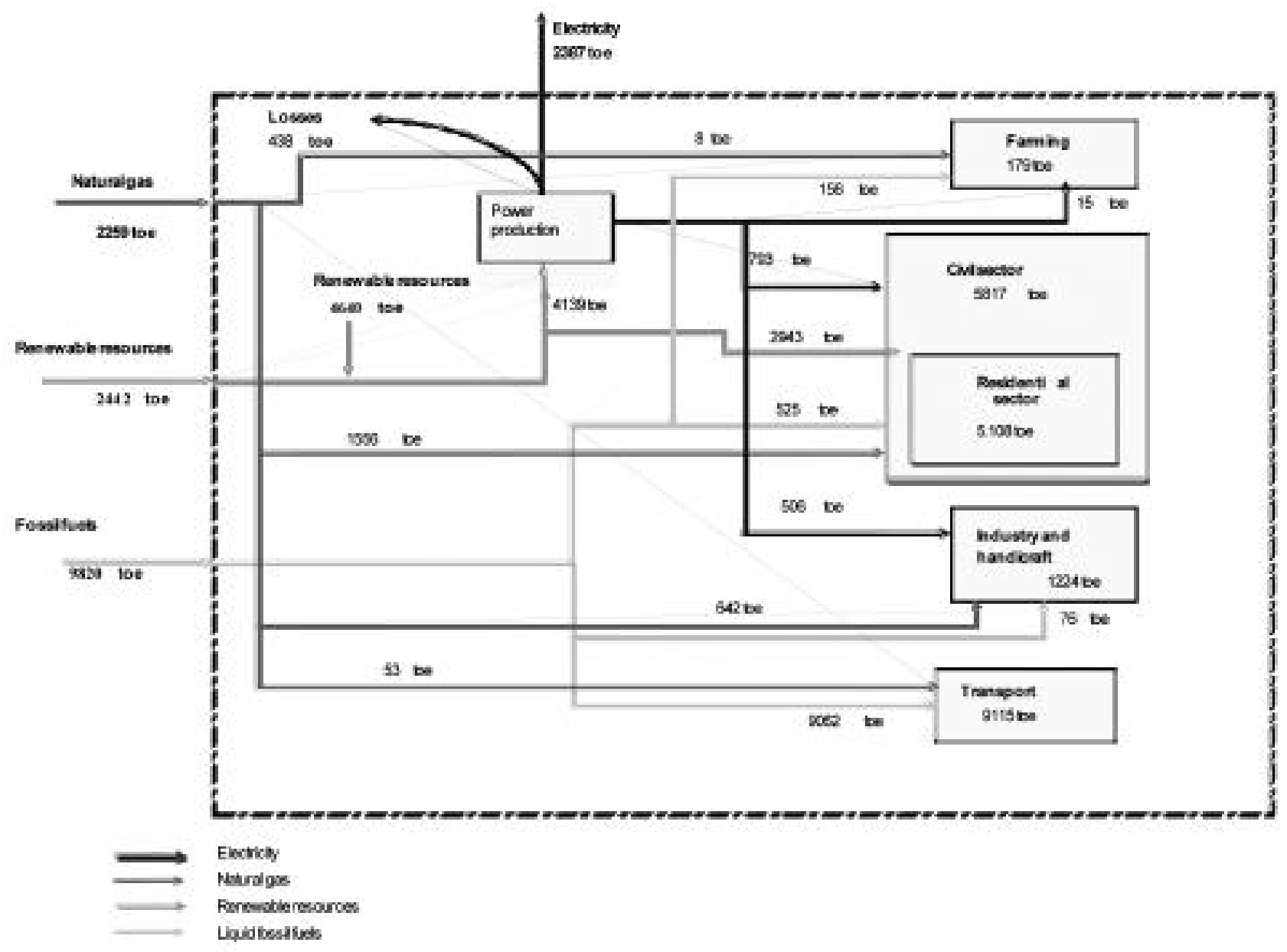

Fig. 2 - Energy consumption in Comunità Montana di Scalve [Aspire 2007]. 


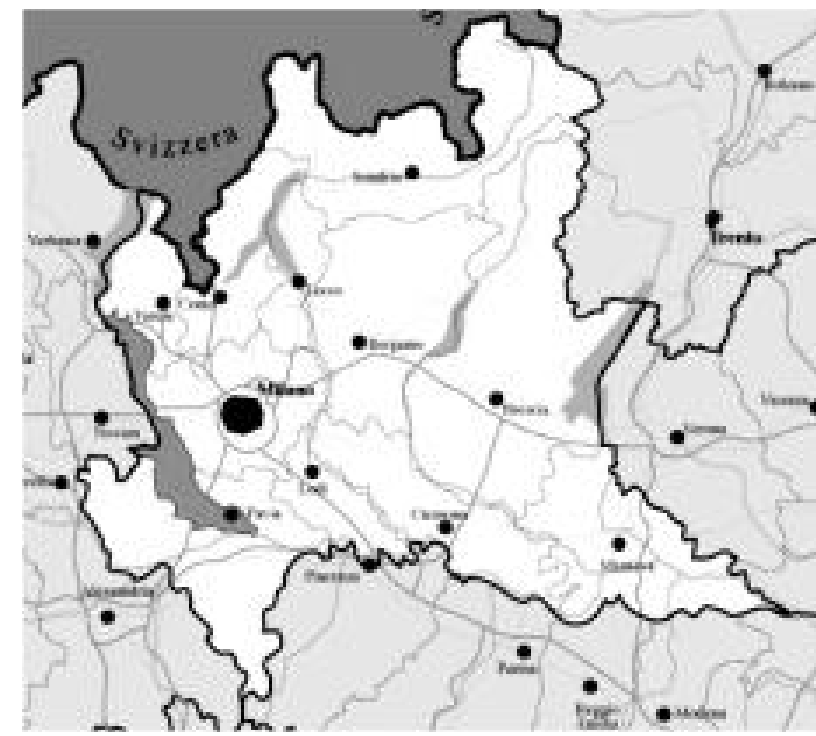

Fig. 3 - Location of Parco del Ticino in Lombardy.

ing renewable energy through the development of special crops serving first of all the civil sector and, where possible, industry (tab. 3). Although the contribution of renewables from agro-forest bio- mass will always be modest in terms of incidence on overall consumption, biomass production could become a significant production sector, creating new or alternative sources of income. In addition, apart from the activities involved in production, whose role is mainly economic, the presence of agro-energy production could also serve as an intellectual stimulus and favour cultural advances.

- it follows that, for example, activities aimed at introducing renewable energy sources in farming and at devising new solutions or technologies should encompass whole districts.

The discussion of these concepts demonstrates that Agricultural Engineering can contribute to the development of production chains that directly convert agricultural raw material (essentially biomass) into energy that can be used for heating.

\section{Biotechnologies and biofuels: a new frontier for agricultural engineering}

\subsection{Background}

Today the production of biofuels for the automotive sector, which falls within the stimulating and

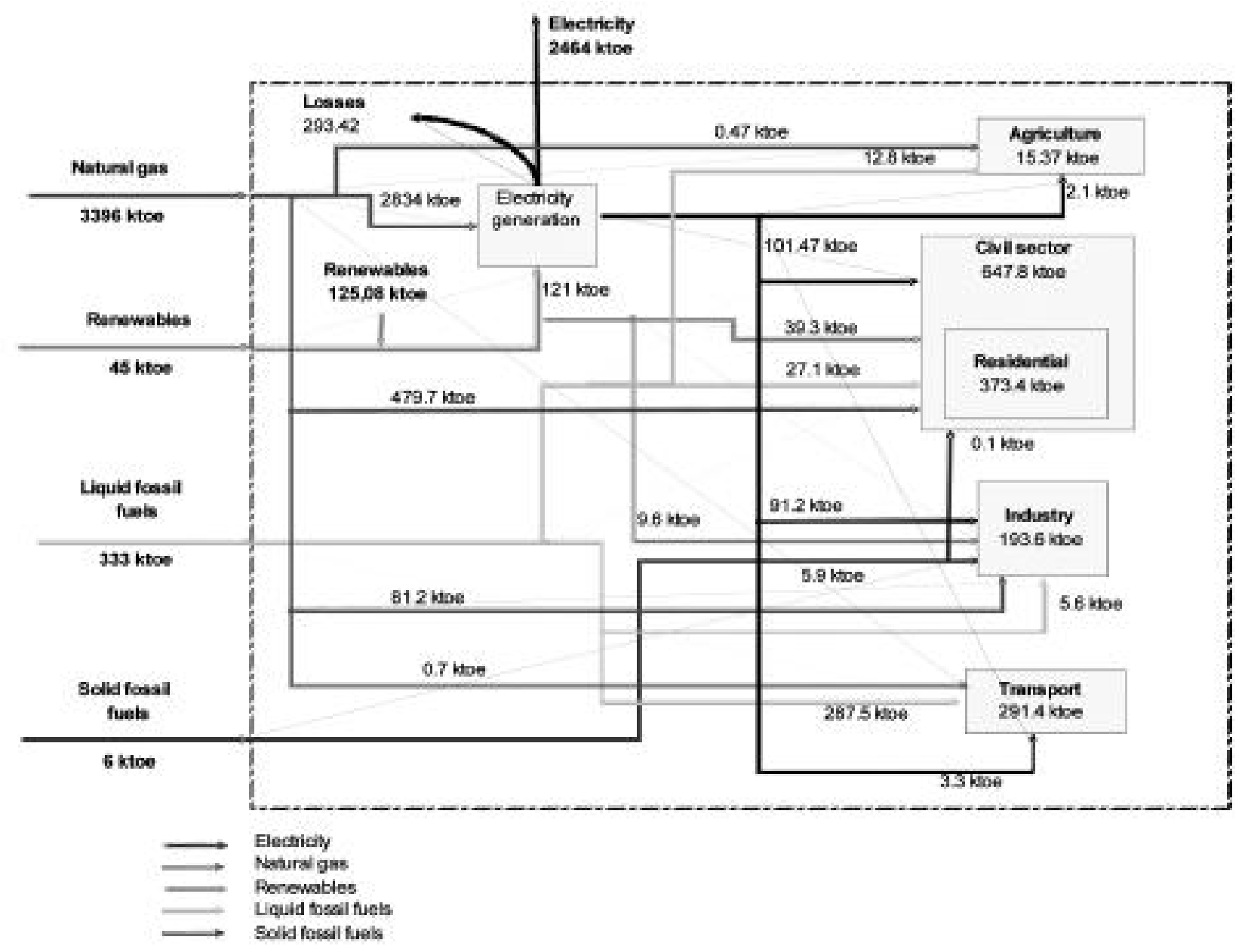

Fig. 4 - Energy consumption in Parco del Ticino [WISE PLAN 2006]. 


\begin{tabular}{|l|l|}
\hline SECTOR & Possible interventions (general indications) \\
\hline \multirow{4}{*}{ Farming } & Introduction of energy crops and co-digestion with manure slurry for biogas production \\
\cline { 2 - 2 } & Development of the forestry biomass energy chain \\
\cline { 2 - 2 } & Diffusion of small wood burners with high environmental standards \\
\cline { 2 - 2 } & Promotion of "model farms" that use technologies based on renewables (solar, biomass, geothermal) \\
\hline \multirow{3}{*}{ Buildings } & $\begin{array}{l}\text { Adoption by municipalities of guidelines, minimum standards and incentives for energy conservation } \\
\text { and the use of renewables (e.g. in building regulations) }\end{array}$ \\
\cline { 2 - 2 } & $\begin{array}{l}\text { Promotion of energy audits (and of relevant interventions) in public buildings in all municipalities; } \\
\text { promotion of energy-related service contracts for municipal buildings }\end{array}$ \\
\hline \multirow{2}{*}{$\begin{array}{l}\text { Energy } \\
\text { production, } \\
\text { distribution } \\
\text { and use }\end{array}$} & $\begin{array}{l}\text { Identification among recent sustainable mobility initiatives of those most suitable for local application. } \\
\text { Eco-driving courses }\end{array}$ \\
\cline { 2 - 2 } & $\begin{array}{l}\text { Renewable electricity production from rivers, canals, etc. Construction of new plants and sustainable } \\
\text { management of existing plants according to minimum vital outflow criteria }\end{array}$ \\
\cline { 2 - 2 } & $\begin{array}{l}\text { Energy conservation from general interventions (e.g. street lighting, water management, industrial } \\
\text { cycles) }\end{array}$ \\
\hline
\end{tabular}

TABLE 2 - Possible interventions for energy rationalization in Parco del Ticino (Source: [WISE PLANS, 2006]).

broad area of the transformation of plant biomass into industrial products (see fig. 5 and [WWF 2008] for examples) is addressed through two substantially different types of processes:

- thermal processes. Gasification of lignocellulosic material produces a CO-rich gas with some $\mathrm{H}_{2}$ (which can be improved through reforming reactions) and other volatile organic compounds, yielding synthetic products, e.g. hydrocarbons, in a catalytic environment. A similar method, based on coal, was used by the Germans during the Second World War (Fisher-Tropsch process) to produce fu-

\begin{tabular}{|c|c|c|c|c|c|}
\hline Biomass chain & $\begin{array}{l}\text { Renewable } \\
\text { energy yield } \\
\text { per surface } \\
\text { unit }\end{array}$ & $\begin{array}{l}\text { Climate- } \\
\text { affecting } \\
\text { gases } \\
\text { avoided }\end{array}$ & $\begin{array}{c}\text { Gross } \\
\text { saleable } \\
\text { production } \\
(G S P)\end{array}$ & $\begin{array}{l}\text { Suitability } \\
\text { for local } \\
\text { conditions }\end{array}$ & $\begin{array}{l}\text { Preference } \\
\quad \text { class }\end{array}$ \\
\hline $\begin{array}{l}\text { Wood energy for heat production by small/medium size } \\
\text { boilers }\end{array}$ & ++ & ++ & ++ & +++ & A \\
\hline Wood energy for biofuel production (pellet) & ++ & ++ & ++ & +++ & A \\
\hline $\begin{array}{l}\text { Oil energy from small/medium size plants producing } \\
\text { - biofuels (oil) } \\
\text { - electricity }\end{array}$ & + & + & $\begin{array}{l}++ \\
++\end{array}$ & $\begin{array}{l}++ \\
++\end{array}$ & $\begin{array}{l}\text { A } \\
\text { A }\end{array}$ \\
\hline Biogas for electricity production & +++ & ++ & +++ & ++ & A \\
\hline $\begin{array}{l}\text { Lignocellulosic biomass energy from medium/large size } \\
\text { plants for electricity production }\end{array}$ & ++ & ++ & + & ++ & A \\
\hline $\begin{array}{l}\text { Oil energy from medium/large size plants for electricity } \\
\text { production } \\
\text { - } \quad \text { seeds only } \\
\text { - } \quad \text { biofuels (oil) } \\
\text { - electricity }\end{array}$ & + & + & $\begin{array}{l}+ \\
++ \\
++\end{array}$ & $\begin{array}{l}++ \\
++ \\
++\end{array}$ & $\begin{array}{l}\text { B } \\
\text { A } \\
\text { A }\end{array}$ \\
\hline $\begin{array}{l}\text { Oil energy for biofuel production (biodiesel) } \\
\text { - } \quad \text { seeds only } \\
\text { - } \quad \text { biofuels (oil) }\end{array}$ & + & + & $\begin{array}{l}+ \\
++\end{array}$ & $\begin{array}{l}++ \\
++\end{array}$ & $\begin{array}{l}\mathrm{B} \\
\mathrm{A}\end{array}$ \\
\hline Alcohol energy for biofuel production (ethanol/ETBE) & + & + & + & + & $\mathrm{B}$ \\
\hline
\end{tabular}

Legend

\begin{tabular}{|c|c|c|c|c|c|c|}
\hline \multicolumn{3}{|c|}{$\begin{array}{r}\text { Renewable energy produced up to } 2 \text { toe/ha } \\
\qquad \begin{array}{r}2-4 \text { toe/ha } \\
>4 \text { toe/ha }\end{array}\end{array}$} & $\begin{array}{l}++ \\
++ \\
+++\end{array}$ & GSP & $\begin{array}{l}\text { up to } 500 € / \text { ha } \\
500-1000 € / \text { ha } \\
>1000 € / \text { ha }\end{array}$ & $\begin{array}{l}++ \\
++ \\
+++\end{array}$ \\
\hline $\mathrm{CO}_{2}$ saved & $\begin{array}{l}\text { up to } 5 \mathrm{t} / \mathrm{ha} \\
5-10 \mathrm{t} / \mathrm{ha} \\
>10 \mathrm{t} / \mathrm{ha}\end{array}$ & $\begin{array}{l}+ \\
++ \\
+++\end{array}$ & & $\begin{array}{l}\text { Suitability fo } \\
\text { for } 1 \text { context } \\
\text { for } 2 \text { contexts } \\
\text { for } 3 \text { contexts }\end{array}$ & $\begin{array}{l}\text { cal context: plains, hills, } \mathrm{n} \\
+ \\
++ \\
+++\end{array}$ & \\
\hline
\end{tabular}

TABLE 3 - Biomass chains and their main technical-economic measures. 
el [www.fisher-tropsch.org]. All of the several operational alternatives are based on the physical disruption of the feedstock into a gas or a liquid, to obtain synthetic compounds with the desired characteristics, usually in a catalytic environment. For example, processes are being studied at the Biomass Laboratory of Università Politecnica delle Marche, Ancona, Italy, to disrupt (liquefy) cellulose and lignin in high-temperature and high-pressure reactors (e.g. $300{ }^{\circ} \mathrm{C}$ and $25 \mathrm{MPa}$ [Peterson, 2008]). The advantage of thermal processes lies in the possibility of working on very different materials, even of fossil origin (e.g., plastic waste);

- biotechnological processes. Disruption and synthesis are achieved via biological processes. In the former case they aim essentially at obtaining sugar substrata for alcoholic fermentation or for conversion into target compounds using enzymes, sometimes specially devised ones. In the latter case, more or less complex previously formed molecules are synthesized into compounds that can be used for varied applications. The advantage offered by these processes usually lies in their greater development potential, environmental compatibility and process feasibility at temperatures and pressures that are close to ambient ones [Mousdale 2008].

In the present context the biotechnological processes are especially interesting. The two critical methods used may be defined as bio-depolymerization (BD) and biosynthesis (BS).

$\mathrm{BD}$ has extensively been investigated ${ }^{19}$, as demonstrated by the abundant literature and the large number of patents, whereas BS has been less widely explored $^{20}$. BS offers promising prospects for the biofuels sector, and has the potential to radically change their characteristics.

As regards biofuels, current processes use fermentable substrates from plant materials, where researchers are trying to increase the sugar mass to initial mass ratio, minimizing cost. The material is converted to ethanol in a hydroalcoholic solution, which requires further, high-energy processing to obtain a reasonably pure form of the molecule (distillation), and additional steps to make it anhydrous (e.g. through molecular sieves). Moreover, since ethanol is an oxygenated, i.e. not highly concentrated product, it would be useful to transform it into a hydrocarbon.

\footnotetext{
${ }^{19}$ As also explained by the fact that the availability of fermentable substrates from discards or waste to obtain, for instance, ethanol, is quite attractive for industry. A leading producer is the Canadian firm Iogen (http://www.iogen.ca/).

${ }^{20}$ In this sector relatively small laboratories can achieve significant results with reasonable investment. Compared with thermal processes, laboratory-developed biotechnological processes are also easier to apply on an industrial scale.

${ }^{21}$ A similar solution is being developed by Amyris Biotechnologies (http://www.amyrisbiotech.com/) in collaboration with Brazil's Votorantim (http://www.votorantim.com.br) at S. Elisa Distillery in Sertõnzinho (State of Saõ Paulo) to obtain by enzyme pathways a 12-C atom molecule similar to petroleum diesel starting from sugar cane juice.
}

Current BS research is working on special enzymes to obtain more interesting alcohols for general use (e.g. butyl alcohol), and very low oxygen $\mathrm{C}_{\mathrm{x}} \mathrm{H}_{\mathrm{y}} \mathrm{O}_{\mathrm{z}}$ compounds, or hydrocarbons that can be separated from the aqueous base by simple mechanical-physical processes $^{21}$ (e.g. centrifugation or decantation). Clearly, eliminating the distillation step would represent a considerable innovation in biofuel production with strong environmental and economic implications and far-reaching consequences.

\subsection{Considerations}

The potential of biotechnologies in sectors such as those described above, especially biofuels, seems to be underestimated in Italy. It is therefore the task of Agricultural Engineering to stimulate research and applications in this area, since the development of novel processes could open the way for new, untapped or neglected production sectors. Agricultural Engineering, together with other disciplines, is a natural participant in the process innovation obtained via biotechnology, because it takes part both in goal definition and in plant development. Its involvement also enables completion of bio-energy chains (e.g. raw material production and processing, waste or by-product management) and interfacing with other primary sectors, like agronomy.

The application of this cultural approach to biofuels could address, for instance, some particularly critical issues in production processes, or pursue the innovation of production systems through the exploration of novel methods and honing of well-established processes. In the former case, it could investigate the scope for reducing the primary energy input in biomass cultivation, to obtain energy products of interest, because raw material production is the most energyintensive and environmentally significant phase. Research could focus on novel methods to produce fertilizers and pesticides (which currently derive from petrochemical processes and consume vast amounts of energy) starting from organic feedstock, including waste and scrap material, and using innovative BDand BS-based methods. In the latter case, interventions could be more innovative, for instance by seeking physical and/or biological processes to replace long-established chemical methods for biofuel production (e.g. biodiesel and/or ethanol). This could be done through collaborations with the national and international biotechnology sector, which is a key player. Interdisciplinary collaborations could lead to even better synergistic and complementary results. This would increasingly make Agricultural Engineering a Biosystems Engineering.

\section{Conclusions}

The above analysis has highlighted the broad scope for the contribution of Agricultural Engineering to the 
renewable energy sector, in particular through three critical aspects: teaching, energy planning and research.

As regards teaching, the need for raising the public's awareness and for spreading the energy culture cannot be underestimated. Teaching of the subject is essential towards the introduction of energy production systems based on non-fossil substrates which, in the case of biomass, are characterized by a limited energy density and involve a complex management. Absence of in-depth knowledge of the matter is likely to prevent success in any effort in this context, including meeting EU targets. Unfortunately, superficial attitudes and erroneous and/or incomplete information have the potential to turn even valuable initiatives into resounding failures. In this context Agricultural Engineering must take on the delicate task of devising and developing innovative teaching pathways that involve and attract students and provide these future members of society with sound knowledge and a critical approach to the production and use of renewable sources.

The teaching issue closely relates to the criteria that need to be adopted for energy planning, particularly the complex criteria that must be devised to analyse highly articulated realities, such as any production area in Italy aiming to co-ordinate actions to prepare, for instance, for the introduction of biomass energy. The most far-thinking local energy plans adopted to date involve the setting up of "virtuous" chains that, mainly starting from local resources, meet some predefined needs without preventing a more rational use of biomass, which could be initially obtained through interventions on user energy efficiency (especially buildings and transport) to reduce draughts and losses. To this could be added the search for a role of local farms as providers of energy-related services and as interfaces with the civil, tertiary and industrial sectors, finding time by time the most appropriate role, not last the teaching aspect if the farm is fully or, more realistically partially, self-sufficient for energy. Agricultural Engineering has full title and the competences to participate in the actions directed at improving efficiency and in energy planning in various sectors, with a large scope for interventions.

The boldest step would be its connection to biotechnologies - which would innovate the traditional distribution of competences appropriated by the various branches of agronomy and biology - also through a search for cultural bonds with apparently distant disciplines, such as those operating in biotechnology research. Whereas in the previous cases it has been possible to provide suggestions, in this case it can only be stated that connections with these disciplines could be the winning move to find alternative routes.

Ultimately, it can be stated that in the three aspects considered, Agricultural Engineering can find important and interesting elements for its involvement in the field of renewable energy sources, whose characteristics require the full range of its competences. Moreover, the spearhead represented by biotechnolo- gy research and its application to biofuels can effectively contribute to make Agricultural Engineering a Biosystems Engineering.

\section{References}

Various Authors, 2009. Climate Change Reconsidered. 2009 Report of the Nongovernmental International Panel on Climate Change (NIPCC), The Heartland Institute, pp 868.

ASPIRE (Achieving Energy Sustainability in peripheral Regions of Europe), 2007. Projects financed by the Intelligent Energy Europe programme.

Berndes G., Hoogwijk M., Van den Broek R., 2003. The contribution of biomass in the future global energy system: a review of 17 studies Biomass and Bioenergy 25(1), 1-28.

Briassoulis D., Panagakis P., Nikopoulos E. (Eds), 2009. Educational and Research in Biosystems Engineering in Europe - LLP Erasmus Thematic Network, pp 155.

Legislative decree 10 August 2005 no. 192 implementing directive 2002/91 relating to the energy efficiency of buildings. Gazzetta Ufficiale della Repubblica Italiana no. 222 of 23 September 2005.

Legislative decree 26 June 2009 no. 59. National guidelines for buildings energy audits. Gazzetta Ufficiale della Repubblica Italiana no. 158 of 10 July 2009.

Directive 2009/28/EC of the European Parliament and of the Council of 23 April 2009 on the promotion of the use of energy from renewable sources and amending and subsequently repealing Directives 2001/7/EC and 2003/30/EC.

European Commission, 2008. COM(2008) 771 final. Communication from the Commission to the European Parliament and the Council.

Flannery T., 2006. The Weather Makers. The History and Future Impacts of Climate Change. Atlantic Monthly Press, pp. 384.

Global Humanitarian Forum, 2009. 2009 Forum Human Impact of Climate Change, pp. 117.

Hoogwijk M., Faaij A., de Vries B., Turkenburg W., 2003. The potential of biomass energy under four land-use scenarios. Part A and B. http://www.fischer-tropsch.org/

Maugeri L., 2006. The Age of the Oil. The Mythology, History, and Future of the World's Most Controversial Resource, Praeger Publisher, USA.

Möller L., 2009. Expanding biogas production in Germany and Hungary. Good prospects for small scale farms? Structural Change in Europe's Rural Regions - Farm Livelihoods Between Subsistence Orientation, Modernization and Non-farm Diversification, Buchenrieder, G., And J. Möllers (Eds.). Vol. 49 of IAMO Studies Series (IAAE 2009 Mini-symposium), pp. 113-133.

Mousdale M.D., 2008. Biofuels, biotechnology, Chemistry, and Sustainable Development. CRC Press - Taylor \& Francis Group, USA, ISBN-10: 1-4200-5125-5, pp. 404.

Peterson A., Vogel F., Lachance R., Froling M., Antal, Tester J., 2008. Thermochemical biofuel production in hydrothermal media: A review of sub- and supercritical water technologies. Energy \& Environmental Science, 1, 32-65. 
Rifkin J., 2002. The hydrogen economy. Tarcher Publishers - Penguin Group, USA, ISBN-10: 1585422541, pp. 303.

UNEP (United Nations Environment Programme), 2009. GLOBAL Green New Deal Policy Brief, pp. 45.

WISE PLANS (Co-operation between Communities for Energy Action Plan), 2006. Projects financed by the Intelligent Energy Europe programme.

WWF, Novozymes, 2008. GHG Emission Reductions with Industrial Biotechnology: Assessing the Opportunities, pp. 91.

\section{SUMMARY}

This paper discusses some considerations and advances a number of proposals about the potential of Agricultural Engineering to contribute to the field of renewable energy, with an emphasis on biomass. Several areas for action are identified. First, general education and teaching of students who will go on to become technicians and professionals in the sector of renewable energies, even though the characteristics of the sectors are still fuzzy. Diffusion of the energy culture, a too often neglected aspect that is however indispensable to sustain the overdue penetration of renewable energies in Italy, is an additional area for action. Another critical area, energy planning, is current- ly viewed mainly as involving the assessment on more or less wide areas of energy consumption and for the scope of replacing fossil resources with renewables to meet some energy requirements. A more complex, overarching issue is energy efficiency, especially of buildings, which should be a mainstay of the planning process but is in fact not so clearly addressed in development plans for renewables. At this same level, all interactions among production sectors should be assessed, to enhance the role of agriculture, one of the new potential energy-producing sectors and one of the possible prospective suppliers of renewable energy for different final users, from households to the service sector and industry. Agricultural Engineering has the skills needed to implement all these different actions. A role for it in advanced research, i.e. biotechnologies, can and should also be envisaged. Its work in the renewable energy sector should closely involve microbiological, genetic, chemical, agronomic, and animal research to define the goals to be pursued and to implement intuitions. In this way, Agricultural Engineering would increasingly be characterized as Biosystems Engineering.

Keywords: Energy in agriculture, Energy saving, Education. 
005_Foppa_Pedretti(567)_35 1-12-2010 9:30 Pagina 46

$\phi$ 